\title{
Wharton Jelly Hair in a Case of Umbilical Cord Stricture and Fetal Death
}

\author{
Eun Na Kim · Jae-Yoon Shim ${ }^{1}$. Chong Jai Kim \\ Departments of Pathology and ${ }^{1}$ Obstetrics and Gynecology, Asan Medical Center, University of Ulsan College of Medicine, Seoul, Korea
}

Placenta forms the intrauterine environment that supplies oxygen and nutrients to the fetus during pregnancy. The umbilical cord is the lifeline of the fetus that connects the fetus to the placenta. An abnormally thin umbilical cord is associated with adverse pregnancy outcomes such as oligohydramnios, fetal growth restriction, and fetal distress. ${ }^{1,2}$ Critical events occurring in the umbilical cord, especially stricture, knots, hemorrhage, and strangulation, often lead to fetal death. ${ }^{3,4}$ Here, we report for the first time an autopsy case of fetal death caused by umbilical cord stricture accompanied by hair growth in the Wharton jelly.

\section{CASE REPORT}

A 28-year-old primigravida woman presented with severe fetal growth restriction and oligohydramnios at 23 weeks of gestational age. Five days later, the ultrasound examination revealed fetal death in utero, and a macerated female fetus weighing 350 $\mathrm{g}(<3$ rd percentile $)$ was delivered. ${ }^{5}$ The circumference of the head was $18.0 \mathrm{~cm}(<3$ rd percentile $){ }^{6}$ and that of the abdomen was $14.4 \mathrm{~cm}\left(<3 \mathrm{rd}\right.$ percentile). ${ }^{6}$ Infantogram showed mildly hypoplastic thoracic cage (Fig. 1A), and chest circumference was $14.6 \mathrm{~cm}$ (10th-25th percentile). ${ }^{7}$ Chromosomal analysis by amniocentesis performed at 18 weeks showed normal findings.

Fetal autopsy and placental biopsy revealed hypocoiling of the umbilical cord (Fig. 1B) with a rather abrupt stricture located $6.5 \mathrm{~cm}$ from the placental insertion. Localized edema of the umbilical cord was associated with the stricture. The diameter of the umbilical cord at the stricture was $4 \mathrm{~mm}$, which was

\section{Corresponding Author}

Chong Jai Kim, MD, PhD

Department of Pathology, Asan Medical Center, University of Ulsan College of

Medicine, 88 Olympic-ro 43-gil, Songpa-gu, Seoul 05505, Korea

Tel: +82-2-3010-4516, Fax: +82-2-472-7898, E-mail: ckim@amc.seoul.kr

Received: August 13, 2018 Revised: September 29, 2018

Accepted: October 24, 2018 lower than the 10th percentile of the normal range (Fig. 2). ${ }^{1}$ Microscopic examination of the umbilical cord stricture revealed hair follicles including hair shafts and papillary mesenchymal body in the firm and fibrotic Wharton jelly. Capillary vessel formation was also found in the peripheral region of the Wharton jelly (Fig. 3). Squames were detected in the alveoli of fetal lungs, and chorionic villi showed increased syncytial knots and distal villous hypoplasia. Overall, the umbilical cord stricture associated with unusual development of hair follicles and fibrotic Wharton jelly seems to have significantly contributed to the fetal demise.

The mother has provided written informed consent for autopsy prior to the postmortem examinations. Since only the pathology and autopsy findings of an already deceased fetus and only deidentified personal information of the mother and the fetus were used, the Institutional Review Board (IRB) of Asan Medical Center determined exemption (IRB number: 2017-1192).

\section{DISCUSSION}

The Wharton jelly is the umbilical cord stroma that originates from the extraembryonic mesoderm of allantois. The Wharton jelly is rich in mucopolysaccharides such as hyaluronic acid and chondroitin sulfate and thus protects umbilical vessels from compression. ${ }^{8}$ Loss of protection by the Wharton jelly can lead to compromised fetoplacental circulation and subsequent fetal death. ${ }^{9}$ Umbilical cord stricture is a known cause of fetal death. Hypocoiling also renders umbilical cord vessels susceptible to kinking and acute obstruction.

The Wharton jelly has been extensively studied as a reservoir of mesenchymal stem cells (MSCs) in the field of regenerative medicine. The Wharton jelly MSCs show a differentiation spectrum covering ectodermal and endodermal lineages. ${ }^{10}$ To the best of our knowledge, the current case is the first example of hair growth and follicle formation in the umbilical cord. It should 

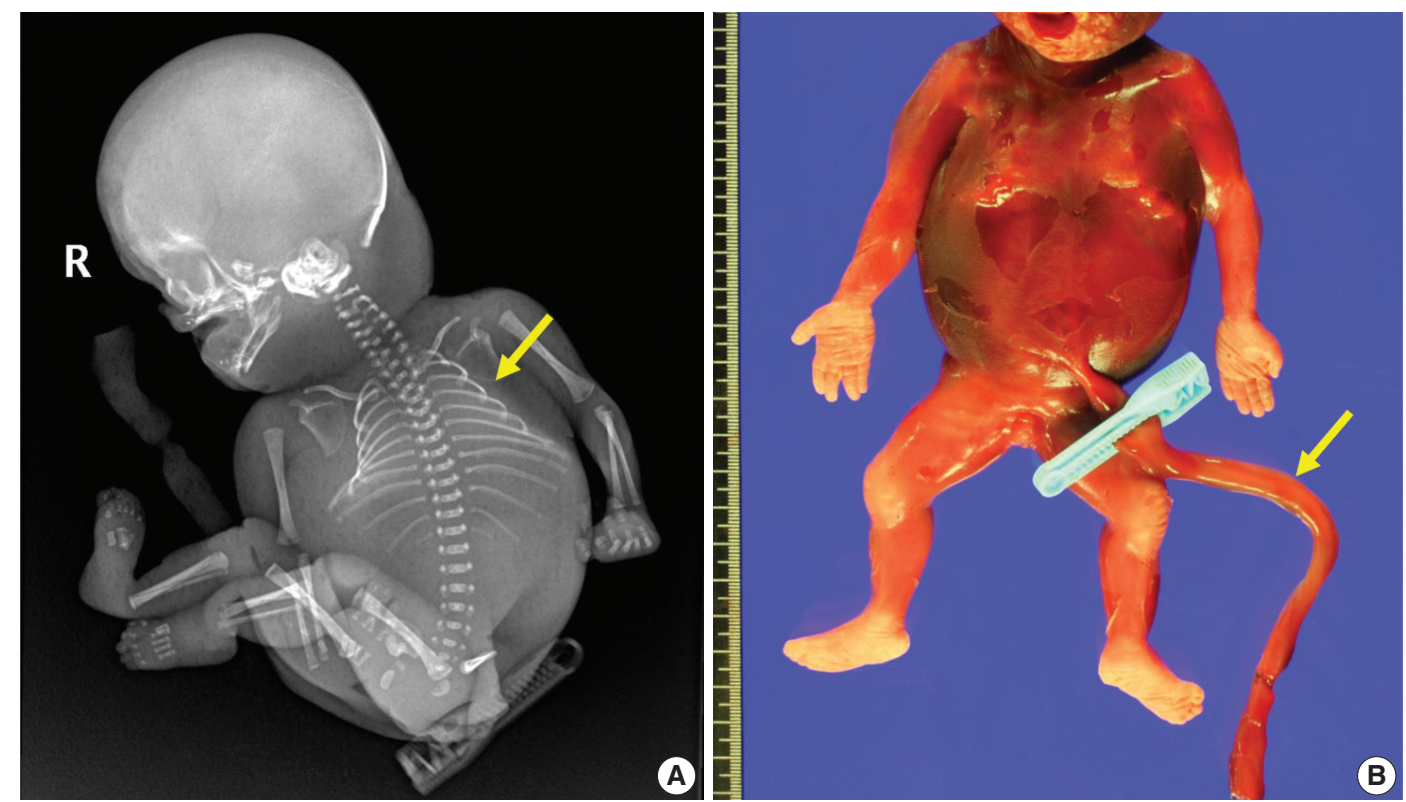

Fig. 1. Major characteristics of the fetus. (A) Infantogram shows hypoplastic small rib cage (arrow). (B) The stillborn macerated fetus has no coiling of the umbilical cord (arrow).
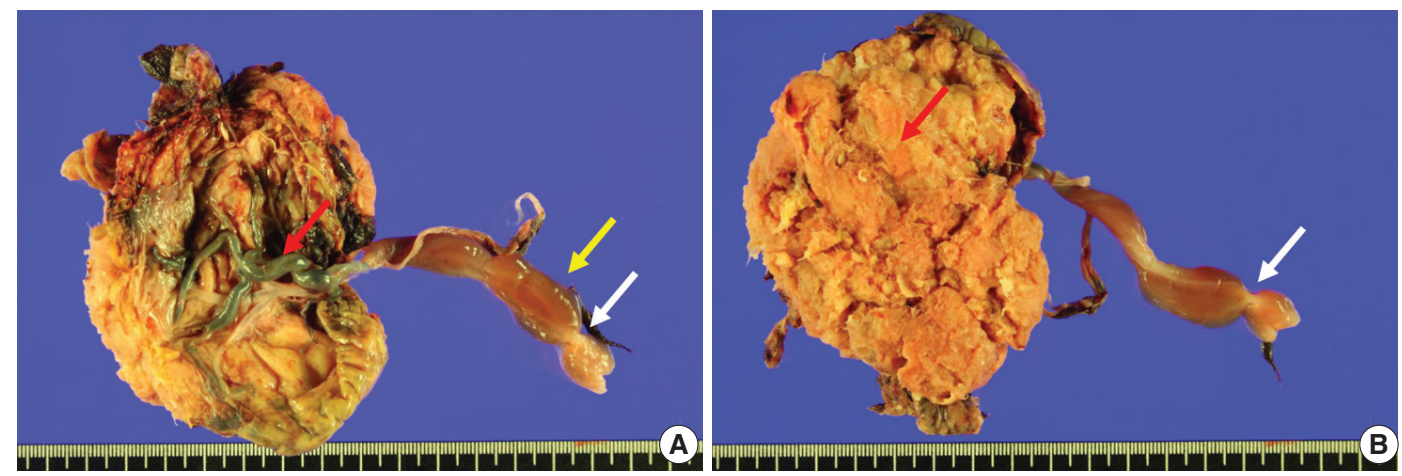

Fig. 2. Gross features of the placenta and the umbilical cord. (A) The umbilical cord is marginally inserted, and the connecting chorionic plate vasculature is tortuous and prominent (red arrow). The umbilical cord shows abrupt constriction (white arrow) and associated segmental edema of the Wharton jelly (yellow arrow). (B) A view from the maternal side of the placenta shows a constriction in the umbilical cord (white arrow). The placental parenchyma is pale and edematous (red arrow).

also be mentioned that hair formation overlaps with a fibrotic change in the Wharton jelly and the development of capillaries. Capillaries are not normally observed in the Wharton jelly, and the anatomical location of the stricture is apart from the umbilicus, where fetal skin tissue can coexist. It is unclear at this point whether the hair and capillaries are products of de novo differentiation of pluripotent Wharton jelly MSCs. The development of multiple capillaries in the periphery and fibrosis of Wharton jelly may be secondary consequences of stricture, and the capillaries can be considered collaterals for compensating for chronically compromised umbilical circulation.

In addition to developmental uniqueness, lessons from the current case include that thorough histologic examination is necessary to determine the cause of fetal death and document significant findings.

\section{ORCID}

Eun Na Kim: https://orcid.org/0000-0003-2992-7881

Jae-Yoon Shim: https://orcid.org/0000-0003-1881-8436

Chong Jai Kim: https://orcid.org/0000-0002-2844-9446

\section{Author Contributions}

Conceptualization: CJK. 

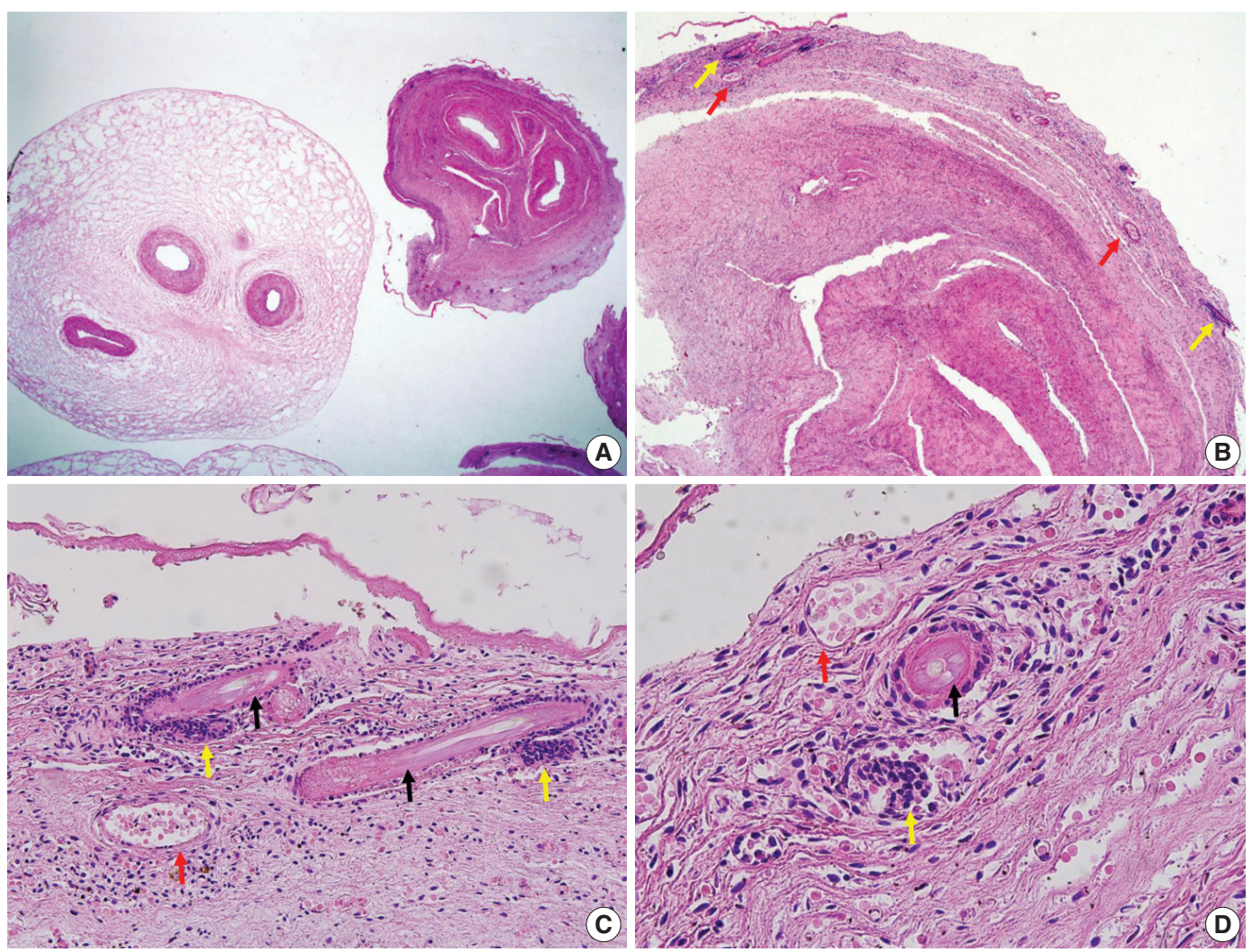

Fig. 3. Microscopic features of the umbilical cord at the stricture. (A) Dense fibrosis of the Wharton jelly at the site of constriction (right) and adjacent edematous Wharton jelly (left). (B) Multiple hair follicles (yellow arrows) and capillaries (red arrows). (C, D) Hair shafts (black arrows) with adjacent papillary mesenchymal body of the hair follicles (yellow arrows) and capillaries (red arrows).

Data curation: ENK.

Investigation: ENK.

Methodology: ENK.

Resources: JYS.

Supervision: CJK.

Visualization: CJK.

Writing_original draft: ENK.

Writing_review \& editing: CJK, JYS.

\section{Conflicts of Interest}

The authors declare that they have no potential conflicts of interest.

\section{REFERENCES}

1. Proctor LK, Fitzgerald B, Whittle WL, et al. Umbilical cord diameter percentile curves and their correlation to birth weight and placental pathology. Placenta 2013; 34: 62-6.

2. Baergen RN. Cord abnormalities, structural lesions, and cord “accidents". Semin Diagn Pathol 2007; 24: 23-32.

3. Horn LC, Faber R, Stepan H, Simon E, Robel R, Wittekind C. Umbilical cord hypercoiling and thinning: a rare cause of intrauterine death in the second trimester of pregnancy. Pediatr Dev Pathol 2006; 9: 20-4.

4. Benirschke K. Obstetrically important lesions of the umbilical cord. J Reprod Med 1994; 39: 262-72.

5. Lee JK, Jang HL, Kang BH, et al. Percentile distributions of birth weight according to gestational ages in Korea (2010-2012). J Korean Med Sci 2016; 31: 939-49.

6. Jung SI, Lee $\mathrm{YH}$, Moon MH, et al. Reference charts and equations of Korean fetal biometry. Prenat Diagn 2007; 27: 545-51.

7. Chitkara U, Rosenberg J, Chervenak FA, et al. Prenatal sonographic assessment of the fetal thorax: normal values. Am J Obstet Gynecol 1987; 156: 1069-74.

8. Benirschke K, Burton GJ, Baergen RN. Pathology of the human placenta. 6th ed. New York: Springer-Verlag, 2016; 403.

9. Peng HQ, Levitin-Smith M, Rochelson B, Kahn E. Umbilical cord stricture and overcoiling are common causes of fetal demise. Pediatr Dev Pathol 2006; 9: 14-9.

10. Aljitawi OS, Xiao Y, Zhang D, et al. Generating CK19-positive cells with hair-like structures from Wharton's jelly mesenchymal stromal cells. Stem Cells Dev 2013; 22: 18-26. 